\title{
Artes de Abrir espaço. Apontamentos para a ANÁlise de práticas em TRÂNSITO ENTRE ARTE E ATIVISMO
}

\author{
Julia Ruiz Di Giovanni ${ }^{1}$
}

Universidade de São Paulo, São Paulo, Brasil

\begin{abstract}
Este artigo de viés teórico discute a abordagem de práticas que transitam entre arte e ativismo a partir dos anos 1990, do ponto de vista de sua relação com a emergência de formas de ação e organização politica. Partimos de algumas análises de episódios de protesto e manifestações (nos EUA, Europa e América Latina) em que "ocupação"e "espaço aberto" se definem como modos de fazer comuns a ativistas e artistas. Refletimos sobre a centralidade dessas noçôes, seja na articulação de ações coletivas, seja na constituição recortes analiticos que visam colocar em foco sua dimensão poética e performática. Em vez de buscar definir a natureza do "artivismo", indagamos as práticas implicadas na criação de espaços politicos de experimentação para problematizar modelos de análise e contribuir com uma perspectiva que nos permita entender como certos gestos e usos atualizam a relação entre experiência subjetiva e a transformação da ordem social.
\end{abstract}

Palavras-chave: estética e política, arte ativista, movimentos sociais, ocupação, espaço aberto, práticas sociais

\section{Entre ARTE e política}

A visibilidade de protestos e grandes mobilizações populares, em diferentes partes do mundo, reativou a partir de 2011 (no caso do Brasil, 2013) questões importantes sobre os mo-

\footnotetext{
1 Departamento de Antropologia, Faculdade de Filosofia, Letras e Ciências Humanas. Doutora em Antropologia Social pela Universidade de São Paulo; autora de Artes do Impossivel: ação de rua no movimento antiglobalização (Annablume/Fapesp, 2012) e Cadernos do Outro Mundo - O Fórum Social Mundial em Porto Alegre (Humanitas/ Fapesp, 2015). É pesquisadora em pós-doutorado (PNPD/CAPES) na linha de Antropologia das Formas Expressivas do PPGAS-USP e uma das coordenadoras do Coletivo ASA - Artes Saberes e Antropologia, grupo de pesquisa vinculado ao mesmo programa. Agradeço aos colegas do Coletivo ASA a leitura da versão inicial deste texto, seus comentários e sugestões fundamentais à edição final. Contacto: juliaruiz@usp.br
} 
dos de ação, expressão e organização social e política. O 15M e a ocupação da Praça do Sol em Madri, as revoltas da chamada "Primavera Árabe", o movimento Occupy nos Estados Unidos, entre outros processos, reinstalaram no cenário político e no imaginário global as praças tomadas por multidões, as imagens de manifestantes desafiando forças policiais e inventando formas de reivindicar, reunir-se, fazer-se ver e ouvir. Assim como nos anos de passagem do século XX para o XXI, no contexto da onda de manifestações que convencionou-se chamar de movimento antiglobalização, uma nova vitalidade dos protestos de rua - sempre cercados por debates sobre sua eficácia e legitimidade - se introduz como elemento irrefutável da experiência social e política do presente. Enquanto proliferam as imagens e discursos a respeito desses protestos, expectativas sobre o futuro também são postas em movimento: nos perguntamos se e como estes momentos de efervescência podem a mudar ordem das coisas. A relação entre as formas da ação coletiva e a possibilidade de transformação das relações de poder se recoloca como problema vivo, em um presente marcado pela concentração de riqueza sem precedentes em nível mundial (Oxfam 2015), ${ }^{2}$ dominado em grande medida pelo sentimento de eminência das catástrofes climáticas provocadas pela ação humana, pela militarização das políticas de controle social sob a pauta do combate ao terrorismo e da guerra às drogas, e, notadamente, pelo desgaste e o descrédito das formas políticas representativas (Nunes 2014:9).

Neste cenário, a emergência do termo artivismo, como categoria analítica, marca um interesse, político e teórico, em formas de ação coletiva cujo efeito e possíveis interpretações não se esgotam na taxonomia da provável orientação ideológica dos participantes, nem na possível funcionalidade que possam cumprir no jogos político-eleitorais e midiáticos das democracias representativas, cuja explicação não termina na identificação dos fatores contextuais, históricos ou socioeconômicos que fomentaram sua erupção. Por um lado trata-se de formas histórica e simbolicamente associadas ao ativismo, ao protesto, a irrupção de processos coletivos de auto-organização, denúncia e reivindicação de direitos, acirrados em momentos de crise econômica e social, que mesmo quando relativamente autônomos em relação às estruturas organizativas e instituições precedentes (partidos, sindicatos, movimentos setoriais), mobilizam recursos e repertórios próprios do campo de relações que nos acostumamos a chamar de política. Ao mesmo tempo, trata-se de experiências coletivas mal contidas pelas fronteiras convencionais da política em sentido estrito, formas de dissenso e reivindicação que mais se aproximam à dimensão cotidiana dos "modos de vida" e "contraculturas" do que das estruturas programáticas e ideológicas que o senso comum atribui aos movimentos sociais. Ao mesmo tempo em que habitam o universo da ação e da organização política, trata-se de modos de intervenção notavelmente ligados a práticas experimentais próprias dos mundos da arte ou, em muitos casos, explicita ou implicitamente informadas pela história do deslizamento da práticas artísticas para fora do campo de autonomia que define a arte moderna, ao encontro de outras dimensões da vida social (Wright 2014:12).

Nos termos propostos pela pesquisadora Ana Longoni para pensar o "ativismo artístico", o desafio é entender em que se funda a radicalidade de práticas que não se prestam a ser analisadas exclusivamente nem sob o critério de sua eficácia política, nem sob o critério de sua natureza "artística" (Longoni 2009:34), já que parecem precisamente ultrapassar as convenções de ambos os campos. Ao apontar, nos processos contemporâneos de mudança social, uma radicalidade ou potência que não pode ser explicada em termos de eficácia institucional ou identidade ideo-

2 O Relatório temático apresentado pela Oxfam International durante o Fórum Econômico Mundial em Davos, Suíça, aponta que até 2016 o 1\% mais privilegiado da população mundial deve concentrar riqueza maior do que a se distribui entre os demais 99\% (Oxfam 2015:2). 
lógica, o termo artivismo propõe um foco de análise dirigido às sobreposições e intersecções entre experiência política e experiência estética. $\mathrm{O}$ neologismo ainda sugere que a análise dessas formas de ação de difícil definição representa um desafio inclusive do ponto de vista lexical: arte, ativismo, estética e política, entre outros termos correlatos, são ao mesmo tempo insuficientes e demasiadamente vagos para dar conta do que queremos descrever.

A proposta deste texto de cunho teórico é delinear alguns problemas relevantes para uma abordagem interdisciplinar dessas formas híbridas, reunidas ainda que provisoriamente sob a noção de artivismo. Faremos isso colocando lado a lado questões transversais a pesquisas etnográficas desenvolvidas por alguns autores sobre formas de protesto e organização política associadas aos ditos movimentos antiglobalização e altermundialistas (Di Giovanni 2012 e 2015) e algumas análises sobre eventos e ciclos posteriores de agitação criativa em diferentes partes do planeta, em particular os movimentos de ocupação de praças públicas no Estado Espanhol e nos Estados Unidos a partir de 2011. O que se pretende não é um exame sistemático desses processos - sobre os quais uma existe bibliografia crescente - mas recuperar nas análises dedicadas a eles um motivo condutor que nos permita apresentar a complexidade dos cruzamentos entre experiência política e criação estética nas formas contemporâneas de ação coletiva. Tomaremos como fio condutor da análise as noções de "ocupação" e "espaço aberto" - comuns às formas políticas ditas criativas a partir da segunda metade da década de 1990 - e discutir sua importância seja como forma recorrente dos processos coletivos, seja na constituição de um modelo de análise que coloca em foco sua dimensão poética e performática. Explicitando alguns dos potenciais e limites dessas noções, encontramos novas perguntas: como se produz uma "ocupação"? Que modos de fazer, dizer ou representar estão implicados na criação de "zonas autônomas temporárias"? Como estas figuras de ação e pensamento atualizam a relação entre estética e política, entre a manipulação das formas sensíveis e a transformação ativa das relações de poder? Tais questões - aqui apenas levantadas - convidam-nos a afastar nosso foco da discussão sobre a natureza do artivismo para propor uma abordagem etnográfica dos modos de fazer que constituem uma dimensão da ação social comum entre ativismos e processos artísticos, enquanto procedimento fundamental à conceituação deste terreno da experiência contemporânea feito de práticas em trânsito entre arte e política, que contravêm e manipulam as fronteiras entre os dois termos.

\section{Protesto criativo}

Em minhas pesquisas etnográficas anteriores, dedicadas a documentos e relatos das formas de protesto de rua nos movimentos antiglobalização entre 1999 e 2001 (Di Giovanni 2012), e mais tarde ao estudo dos discursos e práticas organizativas do Fórum Social Mundial no Brasil entre 2001 e 2005 (Di Giovanni 2015), procurei aproximar-me da dimensão irredutível da prática, das sensações de potência e intensificação que frequentemente marcam processos e episódios de forte envolvimento coletivo com um fazer comum - seja ele ocupar uma praça, sair em passeata, convocar uma reunião, planejar um confronto, erguer paredes ou tomar uma decisão em assembleia. Embora para uma antropóloga em campo trate-se de algo facilmente perceptível - senão incontornável - as sensações dessa potência e as formas pelas quais ela se expressa são dificilmente traduzíveis em termos sociológicos, a ponto de parecerem não ter estatuto adequado ou suficientemente estável para servir de material à análise acadêmica. 
Em que reside a potência política e o caráter "criativo" de uma ação social? Dependem de seus resultados ou impactos externos, de seus fins, de seus meios, ou quem sabe da natureza dos sujeitos que a levam a cabo? Trata-se, como a magia e o mana, de noções nativas de eficácia? Dependem de certas características intrínsecas dessas ações ou de convenções institucionais, tal como a beleza e a autoridade atribuídas às obras de arte? Ainda que não ofereçam respostas, essas mesmas sensações e percepções com relação à potencia de reverberação política ou estética da ação coletiva não podem ser negligenciadas: são talvez algumas das pistas mais importantes de que dispomos para investigar o papel dos movimentos sociais nos processos de transformação social.

Como aponta o historiador André Mesquita (2011), já entre os anos de 1990 e 2000, em países como Estados Unidos, Canadá, França, Espanha, Argentina e Brasil, os modos de recomposição das ações políticas de caráter contestatório, articulados em torno da formação de coletivos e de modos de participação democrática direta, se constituíram em uma relação imediata com processos de experimentação estética orientados para fora do "mundo da arte", em que a autoria dá lugar à produção coletiva e os conceitos oriundos do universo político (e militar) - guerrilha, tática, estratégia - se tornam centrais no processo criativo (Mesquita 2011:17). Essa espécie de "artivismo", em que práticas de artistas e ativistas se confundem, se fez visível ao longo de todo o ciclo contestatório antiglobalização. Em lugares como Seattle (1999), Praga (2000), Quebéc (2001), Gênova (2001), Cancun (2003), grandes manifestações contra os acordos de livre comércio, as políticas do Fundo Monetário Internacional, a autoridade dos chefes de estado do G8 e o poder sem fronteiras do capital internacional, falavam da possibilidade de um movimento social global - não porque apresentassem um programa para a revolução mundial ou mesmo uma pauta de reivindicações unificada, mas porque constituíam uma constelação de ações expressivas que dialogavam entre si, construíam mensagens a muitas vozes, forçando a ruptura do que parecia antes aceitável e possível em termos de ação e organização política (Di Giovanni 2012). Alianças até então impensáveis entre sindicalistas e ecologistas, entre agricultores indígenas e punks anarquistas, carnavais anticapitalistas, vandalismos poéticos, marionetes clandestinas, bailarinos usando máscaras de gás, batalhões armados de pistolas de água, bichos de pelúcia bélicos, fanfarras, rituais xamânicos: afastando-se de uma lógica de reivindicações e resultados, o protesto político se revelava inequivocamente como momento de desorganização e reorganização da experiência social, aproximando-se em seu caráter experimental dos processos de criação artística.

Graças a essa onda de reinvenção das formas de protesto, a criatividade plástica e a atenção à dimensão estética e simbólica das ações coletivas tendem a assumir um lugar cada vez mais importante para os movimentos sociais (Blanco 2014:180). Nos anos 1990, afirma a pesquisadora Julia Blanco, cresce também a reflexão sobre as possibilidades da criação estética como eixo central da dita "ação direta criativa", na confluência de legados das vanguardas dadaísta e surrealista do início daquele século, da arte praticada nos anos 1960, 70 e 80 por grupos como a Internacional Situacionista, o Fluxus e os Provos, do conceitualismo, dos repertórios da desobediência civil, da cultura $p o p$ bem como da contracultura ao estilo faça-você-mesmo (Mesquita 2011; Blanco 2014). Happening, performance e novos termos como artivismo são cada vez mais empregados para tratar também de formas de fazer política.

Como sugere Marcelo Expósito (2014), certos processos políticos coletivos, ao "desacomodar" espaços públicos e subjetividades naturalizadas, talvez estejam de fato assumindo nas últimas décadas a função experimental e disruptiva que as vanguardas artísticas da moderni- 
dade cumpriam tirando proveito para fins subversivos da autonomia relativa de que gozavam no campo estético. E se a experiência prática dos novos movimentos for agora o lugar social onde se pode encontrar os protótipos de "comoção sensorial, estranhamento perceptivo e mutação subjetiva" que antes pareciam restritos àquelas cenas artísticas vanguardistas ${ }^{3}$ (Exposito 2014:226)? Longe de representar uma "estetização" do fazer político em que as formas do poder mudariam de "roupagem" ou "estilo", permanecendo no entanto estruturalmente iguais a si mesmas, as formas de mobilização sensorial, perceptiva e subjetiva produzidas no seio de processos de rearticulação de lutas sociais estão diretamente implicadas nos deslocamentos da própria política, na expansão de seus significados, quando não em uma radical ruptura com os modos de fazer que anteriormente a separavam do conjunto da ação social considerado não-político - em que a arte, por exemplo, tenderia a situar-se. Do mesmo modo, a implicação de uma prática de origem "artística" em um movimento vivo de organização política e ação coletiva força deslocamentos importantes no campo da arte, desafiando os limites do possível também em termos do que é artístico e do que não é.

Ana Longoni fornece um exemplo de práticas que necessariamente embaralham as fronteiras entre arte e política ao descrever as formas de ação desenvolvidas a partir de 1996 na Argentina, onde mais tarde o movimento antiglobalização encontraria um de seus focos mais dinâmicos na América Latina, pela geração dos filhos dos desaparecidos políticos durante a recente ditadura militar (1976-1983), que chegam à vida adulta no auge do processo de privatização e desmonte do Estado argentino, quando novas leis de perdão conferem impunidade aos responsáveis pela perseguição e massacre dos opositores durante o regime autoritário. A partir da criação da associação HIJOS (Hijos por la Identidad y la Justicia contra el Olvido y el Silencio), um série de coletivos e agrupações de $\operatorname{artistas}^{4}$ e ativistas passa a promover ações de denúncia em espaços públicos contra a impunidade dos agentes da repressão, reavivando e expandindo o movimento de direitos humanos que as Mães da Praça de Maio mantinham ativo desde 1977.

As práticas desses coletivos envolviam artes gráficas, contracartografias e encenações teatrais de rua, compondo os escraches - ações diretas que expunham publicamente as marcas da violência ocultas no espaço social e urbano, criando sinalizações para indicar os locais onde a violência da repressão acontecia e as residências e locais de trabalho atuais de conhecidos torturadores, diante dos quais eram encenadas as cenas de tortura, sequestros e esquetes mordazes contra a hipocrisia que os mantinha impunes (Longoni 2009:18-20). Segundo Ana Longoni, essa geração de "filhos" criativos, tendo aprendido com as Madres a potência simbólica que manteve sua coesão enquanto grupo e a visibilidade de sua reivindicação, levou adiante seu próprio modo de fazer, em consonância com as formas de rebeldia e ação direta que emergiam em diferentes partes do mundo no mesmo período. Por exemplo, enquanto as Madres se concentravam em torno dos centros simbólicos do poder da nação (a Praça de Maio), os escraches não dependiam de uma localização específica, podendo multiplicar-se em diferentes pontos da cidade e do país: "onde estiverem, vamos encontrá-los", era uma de suas palavras de ordem (Longoni 2009:21), não estranha ao tema "estamos em toda parte" que o movimento de denúncia das corporações transnacionais e das instituições multilaterais a seu serviço adotaria mais tarde.

3 É da autora a tradução das citações de obras em língua estrangeira.

4 Entre os grupos envolvidos estavam o GAC (Grupo de Arte Callejero), o Etcétera (atual Internacional Errorista), o En Trámite de Rosario, Costuras Urbanas, Las Chicas del Chancho e El Corpiño de Córdoba, Escombros (La Plata), Maratón Marote, 4 para el 2000, La Mutual Argentina e Zucoa No Es (Buenos Aires). 
Ao mesmo tempo em que expandem o campo de ações reconhecidas como políticas, incorporando ao fluxo da ação procedimentos, técnicas e linguagens desenvolvidos fora do contexto de um conflito social específico, a ampliação das formas de protesto e circulação de mensagens políticas também é pouco redutível àquilo que se convenciona chamar de arte. Se há uma dimensão estética desse ativismo, não estamos falando do efeito de técnicas ou retóricas intrinsecamente artísticas: ela é feita de recursos facilmente reprodutíveis, formas populares e corriqueiras de saber e fazer, muitas vezes previsíveis e repetitivas, distantes das convenções de originalidade, autoria e pertinência ao debate intracampo que definem a condição do que é “arte" (Longoni 2009:34).

Os recursos e modos de fazer que se desenrolam nos protestos de rua, como já argumentei em trabalhos anteriores, não constituem apenas uma dimensão expressiva sobreposta a uma infraestrutura social ou ideológica que determina o caráter político e o papel histórico de um movimento social (Di Giovanni 2012:53). A ação coletiva - na arte ou no ativismo - recorta o "sensível comum" (Mesquita 2011:38), cria espaços e temporalidades, altera os limites do que é visível e dizível. As práticas organizativas, comunicativas e táticas de um movimento não apenas representam conflitos sociais, mas criam formas da experiência mesma desses conflitos.

\section{ARtes de ABRIR espaços}

Diferentes autores são enfáticos em destacar que a ocupação de espaços públicos tornou-se uma imagem recorrente nos protestos que atravessaram o mundo após 2011. Willian J. T. Mitchell (2012) identifica essa imagem como o fio condutor fundamental para a interpretação da correlação mimética entre a tomada da Praça Tahrir no Cairo pelos manifestantes que exigiam a queda do regime de Hosni Mubarak e a ocupação da área do Zuccotti Park no distrito financeiro de Nova York pelo movimento Occupy Wall Street. Em ambos momentos "icônicos" do ano de 2011, segundo o autor, as imagens mais importantes não eram as figuras de manifestantes em si (quase invariavelmente anônimos), mas o espaço contra o qual essas figuras apareciam: a grande protagonista destes eventos era a própria ocupação (Mitchell 2012:9). A retórica do espaço e a tática da ocupação são, para Mitchell, as conexões entre os movimentos de Manhattan e Cairo, que em vez de uma tomada do poder, objetivavam "manifestar um poder latente de recusa e criar o espaço fundacional do político [...] que se cria quando as pessoas se reúnem para falar e agir juntas como iguais"(Mitchell 2012:11).

Rodrigo Nunes (2012) refere-se aos mesmos modos de fazer quando identifica o acampamento (e não a assembleia) como principal forma organizativa dos movimentos de 2011. Antes do Occuppy Wall Street, o acampamento que sucedeu os protestos de 15 de maio na Praça do Sol em Madri, na Espanha, é outro episódio fortemente conectado a essa rede de imagens, como afirma Julia Blanco:

[A] ideia de tomar a praça central de uma urbe e instalar-se aí é diretamente inspirada na série de revoluções que acabavam de irromper no mundo árabe. Em especial, a Praça Tahrir, [...] suas tendas que remetem ao elemento de construção típico do deserto, e que agora serve para estruturar a dissidência urbana (Blanco 2014:215).

Segundo Blanco, a Acampada Sol, na medida em que instala no centro da capital espanhola não apenas barracas, mas estruturas organizativas, serviços e trocas, constitui uma espécie 
de "urbanismo" popular de revolta, que servirá por sua vez como referência política e estética para a multiplicação de acampamentos em outras localidades ${ }^{5}$, onde se repetem a estética precária das construções de madeira e papelão, a profusão de cartazes com mensagens poéticas a serem replicados através de fotografias nas redes sociais, bem como a organização de sistemas de atendimento de saúde, bibliotecas, alimentação, etc. Em Sol, Zuccotti Park ou Tahrir, sugere Mitchell, a visibilidade (no centro da praça pública) de modos de estar e fazer funcionar a vida coletiva instala séries de espelhamentos, talvez polêmicos, certamente de grande complexidade política: entre a grande cidade "real" e a pequena cidade utópica temporária, entre as construções e as soluções dos ativistas e os assentamentos precários de refugiados e sem teto, desabrigados que também ocupam as cenas dos noticiários internacionais (Mitchell 2012:14).

Mesmo na ausência de uma reivindicação unificadora clara (como existiu no Egito, ainda que negativa, a exigência da renúncia de Mubarak), os acampamentos não constituíam materializações de uma vontade coletiva dada a priori, mas tentativas de criação de um espaço de experiência em que fosse possível construir vontades compartilhadas e uma força política capaz de expressar, legitimar e fazer valer essas vontades (Nunes 2012:5). Como aponta Nunes, a ocupação sob a forma do acampamento não apenas fornece um ponto de intersecção entre redes sociais concretas e virtuais, mas o faz expondo ativistas com ou sem experiência ao desafio de manter e gerir um espaço físico e recursos comuns. Nesse sentido, "em contextos de profundo desempoderamento e crises severas em sociedades altamente atomizadas, [os acampamentos] funcionavam como um espaço em que o tecido de relações que chamamos de 'a política' poderia, pelo menos para quem estava lá, ser parcialmente (re)constituído” (Nunes, 2012:6). A política aqui é algo que se funde à experiência subjetiva e corporal de ocupar a praça, às relações sociais e sensoriais que a prática da ocupação estabelece. A produção de um espaço de novas possibilidades políticas incorpora uma noção ampla de produção do viver, uma "produção social" que passa pelo trabalho dos sentimentos, dos sonhos, das linguagens e fundamentalmente pela pesquisa de relações não mediadas (ainda que provisoriamente) pela racionalidade mercantil capitalista (Exposito. 2014:220). Julia Blanco também identifica o "espaço liberado" como uma das constantes em que a práxis política e a prática estética se mostram intimamente relacionadas: a ocupação física é ocupação estética, o movimento dos corpos e de tudo o que trazem consigo cartazes, bandeiras, vestimentas, adereços, instrumentos, bonecos, utensílios, móveis - implica a manipulação plástica e simbólica do espaço ocupado (Blanco 2014:272).

As ocupações que marcam o ciclo de protestos de 2011 encontram seus antecedentes mais recentes nas histórias de tomadas de edifícios, bairros, ruas e praças durante os protestos antiglobalização, em que se tornara central ideia de que o objetivo mais imediato de uma manifestação é a liberação provisória de um espaço das ordens político-culturais que o determinam - de um espaço físico, certamente, mas também necessariamente de um espaço de imaginação (Di Giovanni 2012). O conceito que então sintetizava essa concepção da ação direta, presente tanto no gesto de bloquear uma avenida quanto no de destruir o letreiro de uma multinacional, era a TAZ - sigla em inglês para Zona Autônoma Temporária. Criada em 1990 pelo escritor anarquista conhecido como Hakim Bay, a expressão designa uma área "de terra, tempo ou imaginação" liberada, em que a recusa da ordem política imposta se converte em formas positivas de experimentação (Jordan 2012:285). Como gesto essencial da revolta política e como uma espécie de grau zero da construção de futuros comuns, a "liberação do espaço" condensa icono-

5 Em 20 de maio de 2011 estima-se que houvesse cerca de 60 acampamentos em curso no Estado Espanhol e mais 15 em outros países, conectados simbólica e telemáticamente à acampada de Sol (Blanco 2014:264). 
clastia e criação, como define Expósito: o gesto de negação, em que habitualmente uma mistura de fúria e festa despojam os poderes instituídos de sua legitimidade, opera junto com uma dinâmica instituinte, a construção de uma institucionalidade própria (mesmo transitória), que pode aparecer para a racionalidade dominante como uma invenção monstruosa (Exposito 2014: 228).

As noções antropológicas de performance e liminaridade também tem sido empregadas para dar conta da complexidade dessas práticas de abrir espaço que marcam as formas contemporâneas de protesto e reconfiguração dos movimentos sociais (Schechner 1995; Holmes 2007; Mesquita 2011; Di Giovanni 2012, Exposito 2014; entre outros). Em particular, é possível pensar as formas de ação como a ocupação e a noção de Zona Autônoma Temporária a partir das ideias elaboradas por Victor Turner sobre a permanência nas sociedades contemporâneas de momentos excepcionais de suspensão e possível reordenamento ou reacomodação das estruturas culturais. Turner chamou esses momentos de "fenômenos liminoides", marcados pelo mesmo caráter liminar, marginal, que identificara nos processos rituais - "quando o passado está momentaneamente negado, suspenso ou revogado e o futuro ainda não começou, um instante de pura potencialidade em que tudo, tal como era, estremece" (Turner 1982:44) - e apontou sua relação com a crítica social e as formas de arte dedicadas a expor injustiças, ineficiências e imoralidades das estruturas políticas e econômicas contemporâneas. A proximidade da definição de Turner ao modo como será definida a experiência estética e política do "espaço liberado" é notável.

Brian Holmes chama atenção em particular para como as características da experiência do "fluxo" descritas por Turner são de fato definidoras da percepção de que práticas de protesto tais como a ocupação são algo mais do que a mera soma de corpos em um espaço e mais do que um simples meio para a obtenção de outra coisa: "um movimento social em ação é um mundo expressivo em si mesmo, que cria suas leis juntamente com seu território. Turner compara esta sensação de estar em fluxo com a experiência arcaica da communitas, ou seja, da união espontânea e sem mediação com seus iguais" (Holmes 2007:17).

A perspectiva proposta por Turner, nesse sentido, reforça a hipótese levantada por Expósito de que, assim como as vanguardas artísticas que buscaram a superação das convenções e instituições de arte que as limitavam, aquilo que chamamos de protesto criativo busca articular um processo de abertura de espaços "liminares" onde se torne possível produzir dispositivos experimentais, "para que os sujeitos mutem coletivamente, a ordem transtornada se transforme e se prefigure outro mundo possível" (Exposito 2014:226). Essa leitura "liminar" do protesto político, em grande medida, nos ajuda a tornar mais clara a relação entre táticas de ativistas e práticas de artistas, sendo possível analisar ambas como modos de abrir espaço para a rearticulação das capacidades humanas de cognição, afeto e criatividade, criando experiências de revogação momentânea das estruturas normativas de um sistema sociocultural.

É verdade que a categoria da liminaridade de Turner nos permite ver como a criação desses espaços liberados reais ou metafóricos é importante para que a reprodução das estruturas político-culturais possa ser provisoriamente interrompida e novas conexões possam ser produzidas. Trata-se de fato de um ponto de partida fundamental para a compreensão de como determinados arranjos de formas expressivas e disposições subjetivas - ou melhor, seu des-arranjo pelo fluxo da ação coletiva - participam dos processos de transformação social. Como aponta John Dawsey, o que Turner nos ajuda a ver são as performances coletivas como formas de um "poder liminar" - potência que resulta de "seu não-acabamento essencial", seu caráter de "abertura" 
(Dawsey 2007). No entanto, a identificação da similaridade entre as noções de fluxo ou communitas e as experiências produzidas por artistas e ativistas engajados nas mudanças sociais nos deixa ainda muitas perguntas em aberto.

Em primeiro lugar, no quadro das definições que o próprio antropólogo qualificou como "exploratórias", um caráter de abertura liminóide pode ser atribuído tanto às manifestações revolucionárias de denúncia da injustiça social, quanto aos lazeres burgueses do entretenimento: "experimentar o fluxo é estar tão feliz quanto pode estar um ser humano - as regras particulares ou estímulos que detonaram o fluxo, seja um jogo de xadrez ou um encontro de oração, não importam" (Turner 1982:58). Desse ponto de vista, a categoria da liminaridade, embora seja eficaz em descrever a potência do protesto criativo, não é suficiente para distinguir o terreno comum entre arte e ativismo político das formas de jogo, excitação coletiva e fluxo que nada tem a ver com uma intenção de criar mecanismos de subjetivação alternativos à ordem político-econômica dominante. Como entender então a diferença entre a ocupação da Avenida Paulista em um ato político - estritamente proibida e violentamente reprimida - e sua ocupação por comemorações de vitórias de um time em campeonatos de futebol - eventualmente liberada pelas autoridades com presença massiva de forças policiais - ou durante os grandes espetáculos que empresas privadas promovem nas noites de ano novo - estes apoiados pelo sistema de segurança pública e celebrados pelo Estado? O próprio Turner reconhece ter deixado de fora dos conceitos de fluxo e communitas um elemento essencial: o conteúdo dessas experiências; indicando que os processos que descreveu são certamente impregnados pelos símbolos que produzem e pelos quais são produzidos (Turner 1982:59).

Outro problema colocado pela figura do "espaço liberado" na teorização das formas contemporâneas que combinam arte e ativismo é a relação de excepcionalidade que uma noção de ocupação, concebida segundo o modelo de espaço "liminoide" de Turner, estabelece com o restante das experiências sociais. O que o antropólogo chama de "espaço subjuntivo" de uma formação social depende de uma "moldura" que o separa do restante da vida coletiva: para olhar para si, como acontece nos processos liminares ou liminoides, uma sociedade deve "recortar um pedaço de si mesma para inspeção. Para fazê-lo, deve estabelecer um quadro no qual imagens e símbolos daquilo que foi recortado possam ser examinados e, se necessário, remodelados e rearranjados. [...] Estabelecer um quadro (framing) é delimitar em uma fronteira" (Turner 1979:468). De maneira semelhante, retórica da ocupação tende a estabelecer uma fronteira, enfatizar a diferença entre a dimensão cotidiana da vida social, supostamente dominada pela repetição, e o caráter extraordinário das vivências que as ações criativas de artistas ou ativistas são capazes de instaurar. As possibilidades estéticas e políticas produzidas em uma ocupação seriam compreendidas assim como próprias de uma zona relativamente "autonomizada" da experiência social em que as relações normais de força e de sentido parecem estar ao menos temporariamente suspensas e, apenas graças a essa suspensão, passíveis de serem manipuladas pelos sujeitos. A “criatividade", nessa perspectiva, é algo que só se realizaria sob a condição de uma separação metafórica, simbólica, espacial ou temporal - como a que Turner (e antes dele Van Gennep) encontra na fase inicial dos ritos de passagem - necessária para que as outras ordens latentes da vida social possam ser concebidas e experimentadas.

Mas as formas de ação que queremos entender melhor, entre arte e ativismo, não vão justamente no sentido contrário, rompendo fronteiras e molduras que separam os espaços sociais onde é permitido brincar com significados dos espaços onde essa brincadeira se torna uma ameaça à ordem pública, a ser reprimida e criminalizada? O que o "artivismo" tem de mais inte- 
ressante não é justamente seu potencial de expor a natureza fundamentalmente estética e política tudo aquilo que se supõe perdido no continuum "não artístico" e "não político" dominado pela racionalidade da produção capitalista? E o que se desvela no fluxo de uma intensa performance coletiva não é justamente uma potência outra daquelas mesmas práticas que empregamos para sustentar relações e navegar pela vida cotidiana, "práticas que estão no coração da transformação social muito antes que isso tivesse nome"(Wright 2014:25)?

Como conceber formas de ação coletiva que conjuguem as dimensões estética e política quando não se encontra no fluxo acelerado da produção capitalista de mercadorias um desses oásis de experiência comunal? Acompanhando a experiência de acampada da Praça Dewey no centro da cidade de Boston - o Occupy Boston, entre setembro e dezembro de 2011 - o antropólogo Jeffrey Juris (2012) aponta que um dos principais impasses políticos no interior deste movimento era dificuldade que muitos ativistas tinham em imaginar modos de fazer compartilhados que se sustentassem fora do espaço experimental instaurado pela ocupação - o que evidentemente acirrava tensões quanto mais se aproximava o momento da desocupação da praça pelas forças policiais. A necessidade de que a potência criativa do acampamento de alguma forma pudesse ser socialmente distribuída para além da praça ocupada, foi melhor captada segundo Juris por uma iniciativa de "arte pública": alguém produziu centenas de barracas em miniatura e espalhou-as pela cidade, algumas apareceram na praça já desocupada, outras na prefeitura, outras em agências bancárias, entre outros locais (Juris 2012:271). Não é difícil perceber como sujeitos se tornam "artistas do comum" no contexto de uma praça ocupada, de uma ação de protesto, mas como essa experiência incide o que está fora daquelas fronteiras temporárias? Em que consiste, concretamente a ação de ocupar em sua relação com a constelação das práticas associadas a movimentos reivindicativos, tais como fazer greve ou marchar? Que procedimentos e operações a constituem? E quando uma ocupação é desalojada pela polícia, quando o instante de suspensão que a ação instaurava se desfaz, o que resta a dizer sobre aquela criatividade insurgente, sobre as vontades coletivas que aquele espaço produziu? Onde vai parar sobre o que foi aprendido e desaprendido?

\section{Políticas de fazer}

Diante desse problema, é interessante voltarmos à noção de Zona Autônoma Temporária (essa espécie de irmã mais velha da ocupação) e a sua importância para as formas de ação e organização que se articulavam uma década antes das hashtags e acampamentos Occupy. Tal como formulada por Hakim Bey, a TAZ não é um espaço, mas uma espécie de técnica acrobática "como dançar sobre um poste e escapar por uma fresta" (Bey 2001:12). Como a liminaridade de Turner, ela aponta para uma forma essencialmente inacabada da ação social, mas não traça fronteiras: não é um lugar, mas um modo de fazer. Como na definição de tática proposta por Michel de Certeau, estamos no universo da ação que nunca encontra um terreno próprio, a que nenhuma delimitação de exterioridade garante condições de autonomia (De Certeau 1980:60). Como já argumentamos em outro trabalho, quando existe um "espaço aberto", metáfora da possibilidade de experimentação estética ou política, ele foi e está sendo mantido aberto por alguém: não é um lugar, nem um princípio, mas um artefato (Di Giovanni 2015: 185) ${ }^{6}$.

6 A distinção de De Certeau entre "espaço" e "lugar" é paralela à distinção entre a dimensão das táticas e da estratégia: no lugar é uma posição estável e distinta, que duas coisas não podem ocupar ao mesmo tempo, onde "reina a 'lei' do próprio". O espaço é o produto de operações e usos, animado pelo desenrolar do movimento. "O espaço é 
Se há um lugar onde o "poder liminar" de uma ocupação se preserva fora da praça ocupada, esse lugar é o corpo - aquele que Foucault chamou ao mesmo tempo de "utopia" e "topia implacável" (Foucault 1966). Para Marcelo Expósito, reside nos corpos a memória social das sublevações políticas, e através deles se explica a ressonância e os mimetismos complexos entre episódios distintos de ocupação temporária de "espaços falsamente públicos" para subverter suas funções e constituir temporariamente prefigurações de uma nova democracia. Se a ocupação se tornou um paradigma em um ciclo de revoltas das últimas décadas, segundo o autor, é porque "em cada nova insubmissão coletiva os corpos recordam: se produzem acontecimentos em que o movimento em seu conjunto sabe e lembra mais do que a mera soma dos sujeitos conscientes que o compõem" (Expósito 2014:228). Se o momento de um protesto se mostra aberto a outros possíveis, segundo o autor, é porque quando cada corpo ali abre-se aos outros reativa-se uma memória sensível de outras lutas incompletas e expectativas irrealizadas.

De que os corpos se lembram? A ideia de Expósito não é certamente remeter-nos a alguma forma de consciência a-histórica coletiva. Se seguirmos sua hipótese, podemos pensar que as ressonâncias entre tomadas de bairros, ruas e praças através do planeta, antes mesmo de ser uma correspondência entre imagens - como propõe Mitchell (2012), é feita das formas que compõem uma memória dos corpos, daquilo que corpos aprendem e compartilham - atitudes, gestos, técnicas corporais, como as define Mauss: maneiras eficazes pelas quais as pessoas sabem servir-se de seus corpos e que transmitem umas às outras (Mauss [1934] 2003:407). Se voltarmos à noção de táticas de De Certeau, veremos que o ponto de articulação dessas "artes da ocasião", que jamais contam com um espaço de autonomia próprio e estável, é também o corpo humano. "A história começa ao rés do chão, com os passos" (De Certeau. 1980: 147), afirma o autor, ao falar de um espaço urbano que não se produz pelo olhar de cima típico do urbanismo e da ordem pública, mas pelo caminhar das pessoas comuns. Nessa perspectiva, a imagem da praça tomada, à maneira de uma fotografia aérea, cede lugar ao corpo a corpo, ao emaranhado das práticas que tomam a praça: caminhar, sentar-se no chão, ajudar alguém a lavar do rosto o lacrimogênio, trazer cadeiras, fazer curativos nos feridos, montar uma barraca, repartir comida, manter-se em pé, fazer um círculo para a assembleia, levantar a mão para pedir a palavra, pintar mensagens em pedaços de papelão, etc.. As formas icônicas da ocupação - as indispensáveis fotos de praças tomadas tiradas do alto dos prédios - são imagens que se politizam porque capturam o reflexo de certos modos de praticar o espaço aprendidos e lembrados pelos corpos. ${ }^{7}$

Muitas vezes, em casos como os acampamentos e Occupys que se multiplicaram em 2011, é possível afirmar que o que se revela no fluxo da performance coletiva é uma potência outra (antes impensada ou invisível) das mesmas práticas usadas para criar e sustentar as relações corriqueiras do cotidiano: ficar de pé, construir abrigo, discutir, comer, dormir, dançar. Judith Butler (2011) já apontou que pensar essas manifestações de rua em termos de abertura de espaços políticos - de "espaços de aparecimento" na teoria arendtiana - exige hoje que investiguemos a dimensão corporal da ação, sem a qual a persistência, as imagens, os efeitos e o poder da "política das ruas" permanecem presos a concepções demasiado restritas e excludentes do que seja o político. A antropóloga Rosalind Morris, por sua vez, indica que, em vez de reiterar a suposta excepcionalidade dos eventos de tipo liminoide, podemos indagar quais são as operações que produzem tal excepcionalidade: não apenas identificando os gestos que tratam de separar a vida

para o lugar como aquilo que acontece com uma palavra quando é falada, que dizer, pega na ambiguidade de uma efetuação"(De Certeau 1980:173).

7 "[A] imagem, fantasma do corpo experiente e mudo", escreveu De Certeau sobre a dificuldade reduzir em uma análise a experiência das práticas cotidianas (De Certeau 1980:68). 
ordinária do espaço criativo, e sim observando como as práticas corporais circulam entre a (re) produção da vida cotidiana e a invenção político-estética - como a tematização de certos gestos em modos excepcionais (rituais, artísticos ou militantes) lhes confere efeitos políticos distintos (Morris, 2007).

Desse ponto de vista "pedestre", em que não há necessariamente uma descontinuidade entre o usual e sua transgressão, artistas e ativistas se confundem, são todos praticantes de espaços, performances, instalações, esculturas, solidariedades, denúncias, desordens, da memória social e de inumeráveis tecno-tatico-poéticas da vida social. Como afirmam Expósito, Ana Vidal e Jaime Vindel, do ponto de vista de sua confluência com as formas de ativismo, a arte não é apenas uma coleção de "representações estéticas", "mas também ferramentas, técnicas ou estratégias materiais, conceituais, simbólicas, etc.” [...] cujo uso se estende para além do âmbito exclusivamente "artístico"(Expósito, Vidal, Vindel 2012:45). As barracas em miniatura espalhadas por Boston depois de dispersado o acampamento são mais intrigantes se, em vez de vistas como representações de objetos ausentes, forem percebidas como presentificações da mão hábil que as fabricou, um saber fazer da ocupação dando provas de resiliência, manifestando-se em uma nova escala. $\mathrm{O}$ ativismo artístico não se funde à rearticulação das lutas sociais quando fornece espaços circunscritos de autonomia em que formas sociais alternativas estão autorizadas a acontecer, e sim quando propõe a autonomia de práticas e sujeitos com relação às instituições culturais e políticas que pretendem circunscrever esses espaços. Reaproveitando uma formulação de David Graeber (2007:378) para definir a ação direta, podemos dizer que combinar arte e ativismo não é fazer de tudo, até arte, para alcançar a liberdade, mas fazer tudo como já se fosse livre - como se tudo fosse arte. As barracas reaparecem como se, apesar da imposição da ordem, a o espaço imaginado da praça continuasse liberado. "Estamos vencendo" - dizia a famosa pichação durante os protestos de Seattle, difundida por uma fotografia. Atrás de uma fileira de policiais paramentados ao estilo robocop, a frase escrita no muro por uma mão experta oferece uma imagem a ser vista, mas também um modo de ver.

Graeber (2007) faz uma análise muito interessante da relação sobre os dispositivos estéticos na ação direta de grupos anarquistas, buscando entender por que os bonecos gigantes coloridos usados nos Estados Unidos durante os protestos antiglobalização simplesmente enlouqueciam as autoridades, que se esforçavam para destruí-los antes que saíssem às ruas, e os policiais que individualmente mostravam profunda aversão, ódio até, diante da sua aparição. Segundo o autor, os bonecos materializam o principal papel da criatividade artística em protestos políticos: desafiam o privilégio da polícia e das autoridades em geral em definir o que está acontecendo. A ação dita "criativa" é fundamentalmente aquela que desloca continuamente as fronteiras do que é estético e do que é político, que propõe recortes e enquadramentos (frameworks) novos a cada momento. E o que deixa as autoridades realmente confusas, para Graeber, é ver manifestantes insistindo em trocar esses enquadramentos quando bem entendem: o que parecia confrontação vira teatro de rua, depois vira desobediência não-violenta, logo vira circo ou ritual mágico, podendo voltar a ser o que já foi antes a qualquer momento (Graeber 2007:407).

$\mathrm{Na}$ produção de análises teóricas, uma abordagem focada nessas práticas que transitam entre um enquadramento e outro nos desafia a ir além da simples reiteração das potencialidades subversivas do jogo criativo na arte ou na política: sugere no plano metodológico a necessidade de observar e descrever os modos pelos quais são produzidos esses deslocamentos, as técnicas ou táticas que colocam para funcionar experiências percebidas como momentos de excepcionalidade ou suspensão. É importante lembrar que pensar em termos de práticas não significa assumir 
critérios utilitaristas para tratar das formas de fazer política. Muito pelo contrário: aproximar- nos do plano das práticas nos permite considerar os modos de fazer de ativistas e artistas em sua complexidade poética, não-utilitária: como modos de conhecer o mundo e reinventá-lo, estabelecer relações entre forma e sentido, entre manipulação das formas sensíveis, produção e usos das relações de poder. As práticas nesse sentido não são só objeto de elaborações teóricas: são maneiras de pensar em ação, de saber e poder também, como vimos, com o corpo.

Finalmente, é necessária alguma vigilância para que o que chamamos de dimensão artística no contexto de movimentos sociais não termine recebendo o papel inglório de simplesmente designar uma falência em termos eficácia política. Afinal, segundo uma racionalidade estritamente militante, toda essa criatividade e excentricidade nos protestos não acaba desviando a atenção da mensagem política principal? Ao se tornar artístico, o ativismo não se torna ineficaz, porque ao fim das contas, será "só arte": algo que tem valor contemplativo para quem gosta desse tipo de coisa, mas é politicamente inócuo (Wright 2014:12)? Que conceitualização antropológica da própria arte pode nos ajudar a fazer justiça à potência das poéticas de protesto que discutimos ao longo deste artigo? Em 1957, Marcel Duchamp fez afirmações a respeito do que vem a ser o "ato criador": o processo subjetivo e material de produção praticado pelos artistas. Em particular, apresentou a ideia de "coeficiente de arte": a distância existente em qualquer proposição artística entre intenção e realização efetiva - relação aritmética entre o que se pretende mas não se expressa e o que é expresso sem intenção. Como aponta Stephen Wright (2014), é essa distância que impede o que chamamos de arte de esgotar-se no instante em que surge, conferindo-lhe o potencial de evoluir através de suas recepções e reverberações. Falar em coeficientes é sugerir que o "artístico" não consiste em objetos ou eventos, mas em um grau de intensidade e complexidade que pode estar presente em qualquer atividade. "É possível que a arte não seja mais (ou nunca tenha sido) uma prática minoritária, mas algo praticado por uma maioria, aparecendo em coeficientes variáveis em diferentes contextos? [...] Qual é o coeficiente de arte deste ou daquele gesto, objeto ou prática?" (Wright 2014:13). Seria assim uma espécie de competência (e incompetência) socializada: nenhuma forma de ação política correrá o risco de se tornar "só arte", se considerarmos que nenhuma forma de ação política está completamente livre de ser "quase arte".

\section{REFERÊNCIAS}

Blanco, Julia Ramirez. 2014. Utopias artisticas de revuelta: Claremont Road, Reclaim The Streets, La Ciudad de Sol. Madrid: Ediciones Cátedra.

Butler, Judith. 2011. "Bodies In Allience And The Politics Of The Street", apresentação oral em setembro de 2011 em Veneza, no evento The State of Things, organizado por Office for Contemporary Art de Noruega (OCA). Acesso em 18 de febrero de 2015 (http://eipcp. net/transversal/1011/butler/en/print).

Dawsey, John C. 2007. "Turner, Benjamin e a antropologia da Performance: o lugar olhado das coisas.” Pp. 33-45 in Tempo e performance, editado por Matsumoto, R. K.; Medeiros, M. B. De e Monteiro, M. F. M. Brasília: Capes/Universidade de Brasília.

Certeau, Michel de. 1980. L'invention du Quotidien. I-Arts de faire. Paris: Gallimard, 1990.

Giovanni, Julia Ruiz di. 2012. Artes do Impossível: ação de rua no movimento antiglobalização. São Paulo: Fapesp/Annablume. 
2015. Cadernos do Outro Mundo: o Fórum Social Mundial em Porto Alegre. São Paulo: Editora Humanitas/Fapesp.

Exposito, Marcelo. 2014."Todo mi cuerpo recuerda: desorden festivo, mutación subjetiva y devenir revolucionario." Pp. 218-231 in Playgrounds. Reinventar la plaza (catálogo de exposição) editado por Museu Reina Sofía. Madrid: Museo Nacional Centro de Arte Reina Sofía/Ediciones Siruela.

Exposito, Marcelo; Vidal, Ana; Vindel, Jaime. 2012. “Activismo artístico." Pp. 43-50 in Perder la forma humana: una imagen sísmica de los 80 em América Latina (catálogo de exposição) editado por Red Conceptualismos del Sur. Madrid: Museo Nacional Centro de Arte Reina Sofia.

Foucault, Michel. 1966. "Le corps utopique”, transcrição de conferência radiofônica realizada em 7 de dezembro de 1966 pela emissora France-Culture. Arquivo Culture Visuelle, Lhivic/EHESS, Publicação do arquivo: 2004. Acessado em 29 de janeiro de 2015 (http:// culturevisuelle.org/blog/5437).

Graeber,David.2007. "On The Phenomenology Of Giant Puppets: Broken Windows, Imaginary Jars Of Urine, And The Cosmological Role Of The Police In American Culture.” Pp. 375-417 in Possibilities: Essays on Hierarchy, Rebellion and Desire. Oakland/Edinburgh: AK Press.

Holmes, Brian. 2007. "Bodies and flows: táticas e estratégias do produtor de mídia ativista." Pp. 13-26 in Conexóes Tecnológicas organizado por Arantes, P; Canetti, P. e Motta, Renata. São Paulo: Instituto Sérgio Motta.

Jordan, John. 2012. "Temporary Autonomous Zone." Pp.13-26 in Beautiful Trouble - A Toolbox for Revolution editado por Boyd, Andrew e Mitchell, Dave O. Nova York/Londres: OR Books.

Juris, Jeffrey S. 2012. "Reflections on \#Occupy Everywhere: Social media, public space, and emerging logics of aggregation". American Ethnologist, Volume 39, No 2: 259-279.

Longoni, Ana. 2009. "Activismo artístico en la última década en Argentina: algunas acciones em torno a la segunda desaparición de Jorge Julio López." Errata \# - Revista de Artes visuales: El lugar del arte en lo político, 0(0):16-35. Bogotá: Fundación Gilberto Alzate Avendaño.

Mauss, Marcel. [1934] 2003. "As técnicas do corpo. Parte I - Noção de técnica do corpo." Pp. 401-408 in Sociologia e Antropologia. São Paulo: Cosac \& Naify.

Mesquita, André. 2011. Insurgências poéticas: arte ativista e ação coletiva. São Paulo: Annablume/ Fapesp.

Mitchell, W. J. T. 2012. "Image, Space, Revolution: The Arts of Occupation". Critical Inquiry, Vol. 39:8-32. Chicago: The University of Chicago Press.

Morris, Rosalind (2007). "Legacies of Derrida: Anthropology". The Annual Review of Anthropology, 2007, 36:355-389. Nova York: Columbia University.

Nunes, Rodrigo Guimarães. 2012. "The lessons of 2011: three theses on organization”. Mute Magazine (revista online), 7 de junho. Acessado em fevereiro de 2015 (www.metamute. org/editorial/articles/lessons-2011-three-theses-organisation).

2014. The Organization of the Organizationless. Londres: Mute Books/Post Media Lab.

Oxfam. 2015. Wealth: Having It All And Wanting More. - Issue Briefing (Informe temático) Oxford: Ofxam GB para Oxfam International. Acessado em 22 de janeiro de 2015 (www. oxfam.org/sites/www.oxfam.org/files/file_attachments/ib-wealth-having-all-wanting-more-190115-en.pdf).

Turner, Victor. 1979. "Frame, Flow and Reflection: Ritual and Drama as Public Liminality". Japanese Journal of Religious Studies, 6 (4): 465-499. 
1982. "Liminal To Liminoid In Play, Flow And Ritual.” Pp. 20-60 in From Ritual to Theatre: the Human Seriousness of Play. Nova York: PAJ Publications.

Wright, Stephen. 2014. Toward a Lexicon of Usership. Eindhoven, NL: Van Abbemuseum

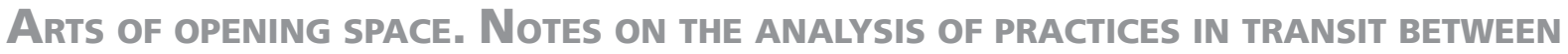 ART AND ACTIVISM}

This paper discusses cientific approaches to the social practices characterised by their transit between art and activism, considering how such practices relate to the emergence of particular forms of political action and forms of organization, based on the analysis, developed by other authors, on protests and demonstrations that took place during the last two decades in Europe, the United States and Latin America, and within which the notions of "occupation" and "open space" define modes of operation shared by activists and artists. The paper reflects on the centrality of such concepts for contemporary forms of collective action, and on the way they became key events for the analytical frameworks anthropologists and other researchers have been building, in an attempt of giving intelligibility to the poetic and performatic dimensions of political action. Thus, instead of trying to define the nature of "artivism", the paper questions the practices implied in the creation of experimental political spaces, as a way of discussing analytical models and searching for a theoretical perspective that enables deeper understanding of how particular gestures and uses actualize the relation between subjective experience and the transformation of the social order.

Keywords: aesthetics and politics, activist art, social movements, occupation, open space, social practice

Recebido em: 2014-01-31

Aceitado em: 2015-06-30 